\title{
Numerical simulation for bolt tension prediction using simplified 2D finite elements model
}

\author{
Fei Yang ${ }^{1,}$, Pengdong Gao ${ }^{1}$, Chu Qiu ${ }^{1}$ and Yongquan $\mathrm{Lu}^{1}$ \\ ${ }^{1}$ High Performance Computing Center, Communication University of China, Beijing, China, 100024 \\ ayangfeiy_f@126.com
}

Keywords: Numerical simulation, Bolted flange connection, Bolt tension, Shigley's formula

Abstract. This paper presents numerical simulation using the 2D finite elements model to determine bolt tension of a bolted joint. The effects of bolt bending and sharing forces will be considered for the analysis of the global mechanical behaviour of the connection. The whole analysis execution is controlled by ANSYS Parametric Design Language (APDL) and the numerical results are compared with Shigley's formula. Experimental results show that the simplified model can be useful for the specific case of bolted connections, as it overcomes the drawbacks exist in traditional formula.

\section{Introduction}

Bolt flange connection is commonly used in various engineer applications. With the increasing of a safety and environmental concern, the tightness of gasket flanged connection becomes an important issue. In addition, since the behaviour of bolt joint is complicated and influenced by several factors such as preload, internal pressure, temperature etc., the clamp force in a joint is the key to maintaining joint integrity [1].

To acquire the best performance of an engine in any operating condition, many analytical tools and experimental methods are used to find the optimum parameters for engine design. Recently, finite element method (FEM) has been widely used in the analysis of flanged connections. The pre-stressing force of bolts maintains the efficiency of the gasket sealing between flanges. Montgomery provided six different kinds of methods and contact element modeling the pretension of bolt joints, the solid bolt can be able to perform the approximate condition [2]. However, another critical factor that affects the sealing efficiency is the behaviour of the gasket material. Abid analyzed and comprised the flange connection using the gasket to none gasket in the pre-tightening and working load conditions, concluded that the use of none gasket can replace the gasket connection [3]. In addition, the influence of internal pressure and temperature in bolt flange connection was also analyzed, with the conclusions that the increase of internal pressure and temperature will enlarge the pulling force of the bolt [4]. However, most available investigations on bolt joint model are based on 3D structural, as the model is complex or with dense mesh, large amount of computing time will be involved.

The aim of this paper is to develop a simplified 2D finite elements model to determine bolt tension under various working loads, considering the effects of bolt bending and share force. Numerical results are compared with Shigley's formula and conclusions are drawn to support the experimental results.

\section{Bolt flange connection theory}

In general, bolted joint consists of a bolt and two flanges, in which, the flanges are clamped with bolt tension force. Fig. 1 shows bolted joint subjected to initial preload and external load, respectively. From bolted flange connection theory, the total tension of bolt is subjected not only to the initial preload and external working load, but also to the stiffness of bolt and stiffness of connected member [6]. The deformation of the bolt flange is followed by Hooke's law.

Assume $C_{b}$ denotes the stiffness of bolt, $E_{b}$ denotes the elasticity modulus, $A_{b}$ denotes the cross section area of the bolt, and the effective clamp length is $1 . \mathrm{C}_{\mathrm{m}}$ denotes the stiffness of member, $\mathrm{T}_{\mathrm{m}}$ denotes its thickness, and $\mathrm{E}_{\mathrm{m}}$ denotes the elasticity modulus. $\mathrm{F}_{0}$ denotes the initial preload, and $\mathrm{P}$ denotes the external working load. 
According to the Shigley's formula [5], during bolt preload (see Fig. 1a), the joint exists only the pretension of bolt, therefore, bolt stretched and connected member compressed in grip share the same preload.

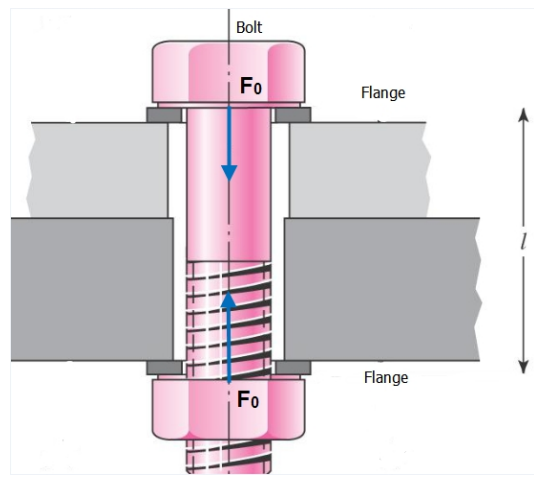

(a)

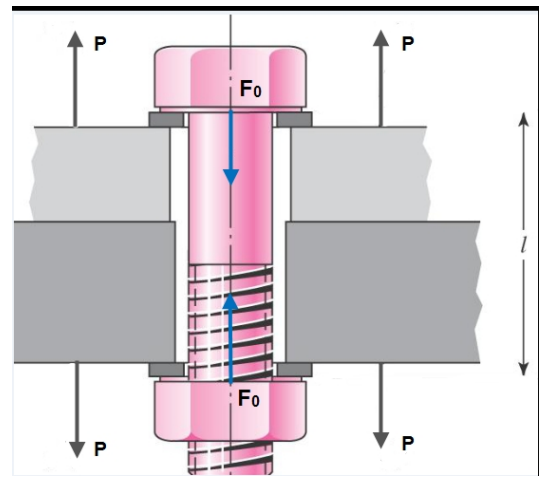

(b)

Fig. 1 a) Initial preload b) Apply external working load.

$$
\begin{gathered}
C_{b}=\frac{E_{b} A_{b}}{l} \\
C_{m}=\frac{E_{m} A_{m}}{l}
\end{gathered}
$$

When external load $\mathrm{F}$ is applied to the joint (see Fig. 1b), the bolt stretches an additional amount $\delta$ and the tensile force of the bolt will increase $\mathrm{P}_{\mathrm{b}}$. The connected parts in grip uncompress same amount $\delta$ due to the bolt elongation. As a result, the amount of the compression force will decrease $\mathrm{P}_{\mathrm{m}}$.

$$
\begin{aligned}
& \delta=\frac{P_{b}}{C_{b}} \quad \text { and } \quad \delta=\frac{P_{m}}{C_{m}} \\
& P_{m}=P_{b} \frac{C_{m}}{C_{b}}
\end{aligned}
$$

Since $P=P_{b}+P_{m}$

$$
\begin{aligned}
& P_{b}=\frac{C_{b}}{C_{b}+C_{m}} P=C P \\
& P_{m}=P-P_{b}=(1-C) P
\end{aligned}
$$

where $\mathrm{C}$ is defined as the stiffness constant of the bolt $C=C_{b} /\left(C_{b}+C_{m}\right)$, indicating the proportion of external load $\mathrm{P}$ that the bolt will carry.

The resultant bolt load $\mathrm{F}_{\mathrm{b}}$ is.

$$
F_{b}=P_{b}+F_{0}=C P+F_{0} \quad F_{m}<0
$$

The resultant load on the members $F_{m}$ is.

$$
F_{m}=P_{m}-F_{0}=(1-C) P-F_{0} \quad F_{m}<0
$$

These results are only valid if the load on the members remains negative, indicating the members stay in compression. However, the above equations assumes that the bending or shear stress has been ignored. 


\section{Finite element models and analysis procedure}

The commercial FEM software ANSYS [7] and ANSYS Parametric Design Language (APDL) [8] macros are developed to control the whole processing. It takes user based parametric input for model geometry, mesh attributes (element type, material etc.), mesh sizing, loads, and results. In this way, a complete finite element analysis can be automated by just assigning input variables, thus greatly reducing the analysis cycle time.

Finite element models. The simplified bolt flange geometry model comprise of three parts, which are bolt, flange and gasket (see Fig. 2a). It is important to have good mesh density in the position of the flange in order to ensure good results for the contact solutions. The mesh element use the PLANE42 unit which contains 2 nodes and 4 dimensional unit. The whole meshed model contains 5,966 nodes and 5,736 2-node finite elements as shown in Fig. 2 b.

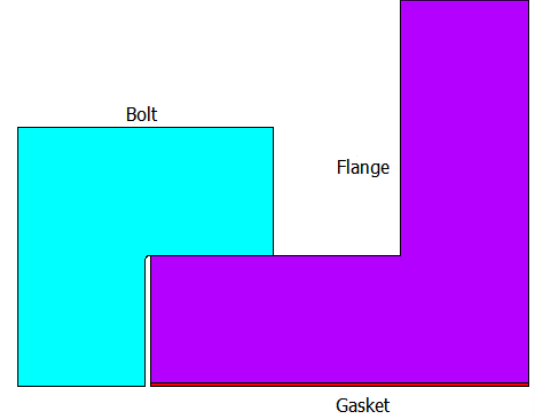

(a)

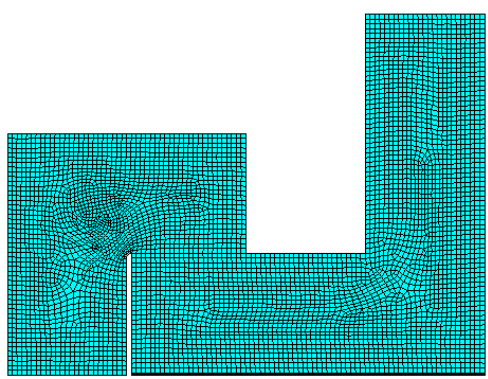

(b)

Fig. 2. a) Geometry model b) Finite element mesh.

Apply boundary conditions. In the bolting-up phase, the bolt is pulled to generate initial displacement at the bolt bottom, and the initial clamp force of bolt was obtained as $15000 \mathrm{~N}$ where the nodes of the displacement were fixed by $0.00161 \mathrm{~mm}$ (Fig. 3a and 3b). In the working phase, the Bolted joints experience repeated load, where external load fluctuates between 0 and $F_{\max }$. The increasing external load was applied at the jointed interface with the rate of $1000 \mathrm{~N}$ until the load reached the maximum value $13000 \mathrm{~N}$ (Fig. 3c).

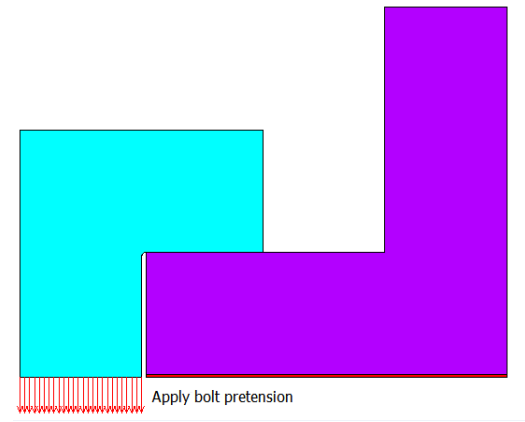

(a)

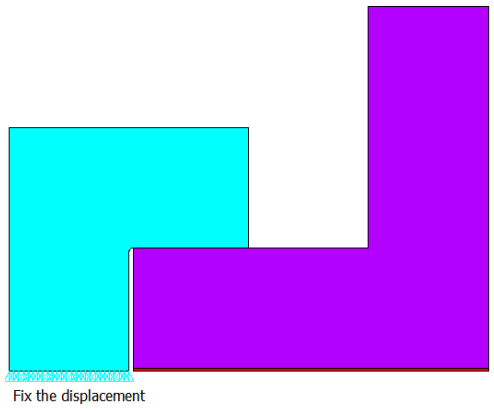

(b)

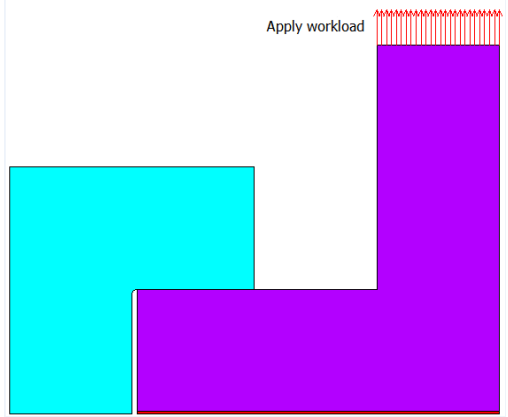

(c)

Fig. 3. a) Apply bolt pretension b) Fix the displacement c) Apply workload.

\section{Results and Discussion}

After solving all the steps, the final bolt tension are retrieved from database by post processing. Fig. 4 plots the results from FEM in comparison to Shigley's formula. In FEM, the obtained bolt tension is decreasing at first, and then increasing with the working load becomes higher. Due to existence of shear force, the bolt has a tendency to bend and the axial force will decrease when the working load is applied first, with the increasing of the working load, the bolt subjected to the more axial force. Therefore, the axial force is start to increase from step 5. However, the calculated bolt tension load from Shigley's formula is proportional to the working load, as the Shigley's formula considers only the 
axial direction, ignoring the bending or shear stress. As a result, it can be seen that the FEM can simulate the behaviour of bolt joint more accurately than traditional formula.

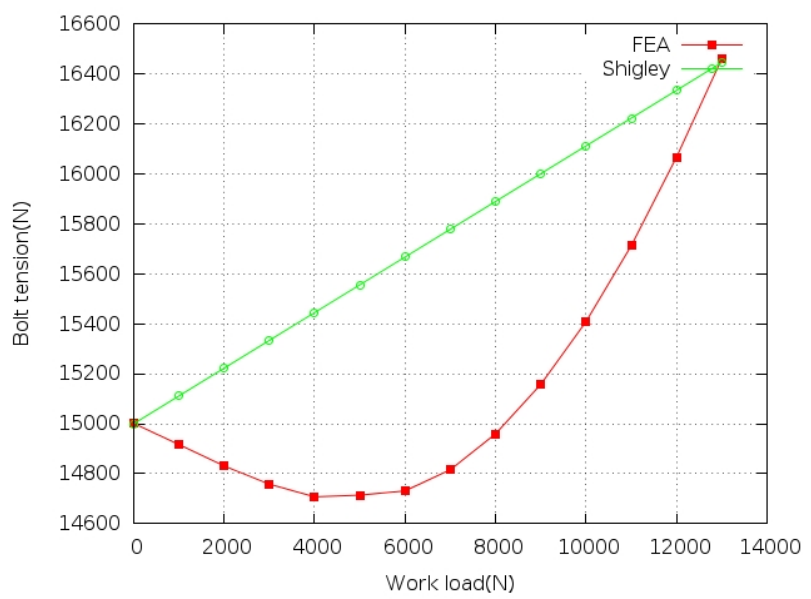

Fig. 4. Numerical and Shigley's formula values comparison for bolt tension.

\section{Conclusion}

In this paper, a simplified 2D bolted flange model is presented and results from FEM are compared with Shigley's formula. Results shows that the simplified 2D finite element model can be useful in such bolted flange connection and reflects more accuracy than empirical formula in determining the bolt tension. Further work will be carried out to evaluate the proposed method on model from other application.

\section{References}

[1] H.-Y. Hwang, "Bolted joint torque setting using numerical simulation and experiments," Journal of Mechanical Science and Technology, vol. 27, no. 5, pp. 1361-1371, 2013.

[2] J. Montgomery, "Methods for modeling bolts in the bolted joint," in ANSYS User's Conference, 2002, vol. 5.

[3] M. Abid and D. Nash, "Comparative study of the behaviour of conventional gasketed and compact non-gasketed flanged pipe joints under bolt up and operating conditions," International Journal of Pressure Vessels and Piping, vol. 80, no. 12, pp. 831-841, 2003.

[4] M. Abid, "Determination of safe operating conditions for gasketed flange joint under combined internal pressure and temperature: A finite element approach," International journal of pressure vessels and piping, vol. 83, no. 6, pp. 433-441, 2006.

[5] J. E. Shigley, R. G. Budynas, and C. R. Mischke, Mechanical engineering design. McGraw-Hill, 2004.

[6] S. Fernando, "An engineering insight to the fundamental behaviour of tensile bolted joints," Steel Construction, vol. 35, no. 1, p. 1, 2001.

[7] A. Release, "10.0 Documentation," ANSYS Inc, Canonsburg, PA, 2005.

[8] E. Madenci and I. Guven, The Finite Element Method and Applications in Engineering Using ANSYS®, vol. 1. Springer, 2005. 